\title{
Evaluating the Impact of a Virtual Reality Workstation in an Academic Library: Methodology and Preliminary Findings
}

\author{
Zack Lischer-Katz \\ University of Oklahoma, USA. zlkatz@ou.edu \\ Matt Cook \\ University of Oklahoma, USA. mncook@ou.edu
}

Kristal Boulden

University of Oklahoma, USA. ksb@ou.edu

\begin{abstract}
Collections of 3D models and the analytic affordances of virtual reality (VR) systems can be integrated to form a "3D digital heritage ecosystem" (Limp, et al., 2011), providing a potentially richer and more intuitive learning environment that enables students to interact with models of artifacts and spaces that are too rare, fragile, or distant to access directly. This paper describes efforts to evaluate the impact of virtual reality on undergraduate instruction in varied disciplines, hosted within an academic library context. Existing research on VR and learning has focused primarily on domain

-specific tasks carried out in controlled lab settings or the social aspects of immersive virtual worlds. This paper describes the methodology and preliminary findings of a mixed-methods research project currently underway (running from September 2017 to August 2018) that is evaluating how use of virtual reality impacts undergraduate students' self-efficacy, and seeks to understand students' embodied experiences. The strengths and weaknesses of the methodology, initial findings drawn from the early stages of data analysis, and directions for further research are discussed.
\end{abstract}

\section{KEYWORDS}

Virtual reality, 3D visualization, self-efficacy, academic libraries, instructional technology

\section{INTRODUCTION}

Following periods of experimentation and, ultimately, failure to reach mainstream adoption - starting in the late 1980s and continuing into the early 2000s - virtual reality (VR) technologies have returned to mainstream consciousness. With the release of the Oculus Rift headset in March 2016, followed closely by the HTC Vive in April 2016, high-fidelity VR has become affordable for a growing segment of the population, including scholars. Educational institutions are now actively exploring the benefits of VR technologies and are beginning to integrate them into academic research and instruction. Paired with highresolution digital 3D models, which can take the form of cultural heritage artifacts, scientific models, or medical imaging data, VR can be used as a powerful analytic platform that engages users' embodied movements, stereoscopic vision, and wide angle of vision to enhance understanding.

Together, collections of 3D models and the analytic affordances of VR systems can be integrated to form a "3D digital heritage ecosystem" (Limp, et al., 2011), providing a potentially richer and more "natural" learning environment that enables students to interact with models of artifacts and spaces that are too rare, fragile, or distant to access directly. Furthering their role in providing curation, infrastructure, and training services for both traditional and emergent forms of information resources, academic libraries have become sites of VR deployment. Existing research on VR and learning has focused primarily on domainspecific tasks carried out in controlled lab settings or the social aspects of immersive virtual worlds.

This paper describes efforts to evaluate the impact on student learning of a custom-built VR application being implemented by staff at the academic library of a large research university that is being used to enhance undergraduate instruction in varied disciplines, specifically Biochemistry and Anthropology. It describes the methodology and preliminary findings of a mixedmethods research project currently underway (running from September 2017 to August 2018) that is evaluating how use of this VR system impacts the self-efficacy of undergraduate students and seeks to understand their embodied experiences with VR. A pre- and post-test survey was used to measure the impact of VR-based class assignments on students' self-efficacy, which was followed by semi-structured interviews that asked students to interpret their experiences of the VR environment. The main research objectives of this project are to:

1. Design a VR workstation that can effectively utilize embodied and immersive affordances to enable students in multiple disciplines to effectively analyze rich $3 \mathrm{D}$ content.

2. Develop tools for evaluating the impact of the VR workstation on student confidence and their learning experiences. 
Following the literature review, initial findings drawn from the early stages of data analysis, the strengths and weaknesses of the methodology, and directions for further research will be discussed.

\section{LITERATURE REVIEW}

\section{Virtual Worlds and Learning}

Existing research literature on virtual environments and learning that predates the latest wave of VR technologies has been focused primarily on Second Life (Praslova-Førland, et al., 2006; Bronack, et al., 2008; Holmberg and Huvila, 2008; Warburton, 2009; Dalgarno \& M. Lee, 2010; Hew \& Cheung, 2010; Sheehy, 2010) and how it can emulate the benefits of traditional learning environments (Deutschmann and Panichi, 2009; Carr, et al., 2010); supporting library engagement with patrons (Haycock and Kemp, 2008) and collaboration in the workplace (Tan, et al., 2012). The virtual environments studied in these research projects employed 3D, computer screen-based visualizations, rather than the current immersive VR head mounted displays (HMDs), however, they demonstrate a research interest in studying how virtual simulations of spatially-oriented environments impact student learning.

\section{VR and Spatial Cognition}

More recent empirical research conducted in computer science, engineering, and cognitive psychology suggests that VR has the capability to be a particularly effective tool for supporting analysis and learning in academic disciplines in which the object of study is inherently spatial (Donalek, et al. 2014). This includes design-oriented fields such as Architecture, as well as the fields of Archaeology, Librarianship, Engineering, and Anatomy (Angulo, 2013; Cook 2018; Seth, Vance, and Oliver 2011; Van Dam, Laidlaw, \& Simpson; Jang, et al., 2017). VR can be a low-cost alternative that enables engagement with this and other content that may be difficult to access (Limp et al., 2011).

VR also affords high visual fidelity for users (i.e. close correspondence to the perception of reality). Ragan, et al. (2013) show that visual fidelity depends on three characteristics of VR systems: 1) the ability to deploy visual content in 360 degrees around the user; 2) sensors to track the head and upper body to provide interactivity; and 3) the presentation of a slightly offset, stereoscopic image to each eye, which enables depth of field perception. These researchers focused on a combination of three characteristics, which, when deployed in tandem, “...produce visual stimuli with a higher level of similarity to real-world stimuli" (Ragan, et al., 2013, p.1). This combination of characteristics translates to a wider and deeper visual field for the user, resulting enhanced capabilities for analyzing and interacting with 3D digital content.

Laha, et al. (2014) identified a set of task-types (searching, making spatial judgements, and describing shapes) that are especially well supported by virtual reality. Qualitative data generated in the study supported these findings, suggesting that the perceived difficulty of tasks related to searching and making spatial judgements decreased while confidence in the participant's ability to describe shapes was improved with virtual reality.

\section{VR Technology and Domain-specific Scholarship}

Research domains are beginning to take advantage of the benefits of VR to support scholarship. For example, Van Dam, Laidlaw, and Simpson (2002) deployed more than 250,000 archaeological discoveries in a virtual environment for researcher analysis, which resulted in the generation of novel insights due to the researcher's ability to quickly scan a large number of individual artifacts within their real-world spatial context (e.g., the dig site's stratigraphy). In this case, VR supported the researcher's embodied engagement with highly detailed representations of archeological data, making analysis more efficient and generating new discoveries.

\section{DEVELOPING TOOLS FOR A 3D ECOSYSTEM}

Existing research literature suggests the benefits on learning and knowledge production of immersive VR visualization tools for analysis of spatially-oriented data types, however the benefits of VR as a pedagogical tool have not been studied in the context of academic library-supported course integrations. Since 2016, the authors have sought to address this gap by developing VR workstations at their home academic library to bring these benefits to faculty and students in as many fields as possible. Incorporating VR into existing library services is important because it is an essential part of the mission of academic libraries to provide the tools and training necessary for faculty and students to engage with information resources of all types.

The custom-designed virtual reality workstations used in this study are comprised of commercially-available hardware and a blend of commercially-available and locally-developed software. On the hardware side, each station consists of a moveable chair-on-rails, coupled with a high-end gaming PC and an Oculus Rift HMD (head mounted display). The LeapMotion handtracking controller and a SpaceConnextion 3D mouse complete the hardware assembly. This set of components was chosen by Emerging Technology Librarians to satisfy two practical design criteria: 1) enable full range-of-motion for users; and 2) cable management. Informal usability testing using Brooke's (1996) usability survey revealed that headset cabling and potential 
obstruction from real-world objects could interfere with users' experiences of immersion in VR (Forsberg, Katzourin, and Wharton 2008; Bowman \& McMahan 2007).

Regarding the custom learning software used in the workstations, in-house development efforts utilized the Unity3D game design software suite as well as plugins necessary to support the peripheral hardware (e.g., the LeapMotion SDK). Growing demand for custom virtual reality experiences from faculty, students, and administrators led to the development of a disciplineagnostic VR "sandbox" where any 3D content from any academic field - within a range of acceptable 3D file types - could be rapidly uploaded to VR for analysis and manipulation across a network of VR headsets. Analysis and manipulation entails using the 3D mouse to orbit educational 3D content, leveraging the expanded visual field benefits and immersiveness of the technology. Additional tools were developed incrementally and included: orientation and scale controls; ambient lighting controls (including "sun" direction and intensity); "tour" mode; annotation tools; and screenshot and video capture capabilities. Study participants had access to all of this functionality. See Figure 1 below for a screen capture from the custom VR software that was developed.

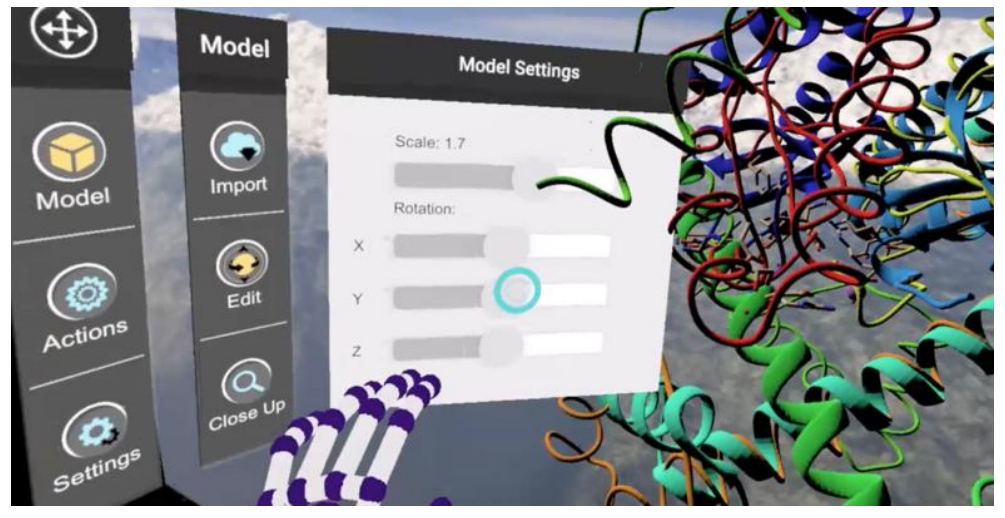

Figure 1

Since being made accessible to the university community starting in January 2016, these VR platforms have been successfully deployed in classes in a range of disciplines, most notably Anthropology and Biochemistry. In order to begin to evaluate the impact of these workstations on student learning, we contacted faculty members who had used the VR workstations in their classroom assignments. A faculty member from the Biochemistry Department and a faculty member from the Anthropology Department agreed to assist us in recruiting undergraduate research participants and developing a classroom activity that would draw on the benefits of VR technology and enable us to evaluate its impact on students. The remainder of this paper describes the methodology of this study and initial findings.

\section{THEORETICAL FRAMEWORK}

In order to produce a holistic understanding of the impact of VR on student learning in a real-world educational context, in designing our research methodology we drew on a theoretical framework that enables analytic insight into changes to students' beliefs (drawing on self-efficacy theory) and their interpretations of their embodied experiences (drawing on interpretive phenomenological analysis).

Self-efficacy theory helped guide the development of the surveys we used. The pre- and post-test surveys were designed to measure dimensions of students' self-reported self-efficacy, with changes in scores reflecting the impact of the VR activity. This theory was first developed by Bandura (1977) and has seen a variety of applications in psychology and education research. Abbitt (2011) explains "self-efficacy theory suggests that the beliefs concerning one's ability to affect a desired outcome influences both thought and action. In general, it is expected that higher self-efficacy beliefs will function as a positive support for action, whereas lower self-efficacy beliefs can have hindering effects on the decision to proceed with a particular course of action" (p.136). Using self-efficacy theory enables a more holistic understanding of the impact of VR use on students compared with using task completion metrics of efficiency and speed (as in Laha, et al., 2014). Abbitt (2011) suggests that improvements to self-efficacy may depend on embodied experiences and affective dimensions related to the success or failure of task completion and their perceived difficulty. To complement the analysis of self-efficacy, we turned to interpretive phenomenological analysis (IPA) to guide the generation and analysis of qualitative data (analysis of this data is ongoing and will appear in a future paper).

IPA is a theoretical and methodological framework that adopts a phenomenological attitude to the generation of qualitative data, with the analysis of that data guided by the assumptions of hermeneutics. IPA supports the interpretation of the lived experiences of participants. It also acknowledges that analysis is a "second-order hermeneutics," i.e. the research is always 
interpreting how participants themselves interpret their experiences (Smith, et al., 2009). Since participants are retrospectively interpreting their experiences, in this study, this could even be conceptualized as "third-order hermeneutics." This applicability of IPA to LIS research was described by VanScoy and Evenstad (2015). Phenomenology as a research perspective has seen increasing applications in LIS research (e.g., Dalbello, 2005; Suorsa and Huotari, 2014; Suorsa, 2017), with its fundamental assumptions outlined for an LIS audience in Budd (2005) and Budd, et al. (2010).

\section{RESEARCH DESIGN}

This research employed a mixed-methods approach, incorporating the generation and analysis of quantitative data (in the form of self-efficacy metrics collected via survey questionnaires before and after the VR activity) and qualitative data (in the form of semi-structured interviews).

The survey questions (see Table 1, below) were designed to measure students' self-reported measures of self-efficacy along the dimensions of general self-efficacy (Qs 1-2), educational self-efficacy (Qs 3-4), spatial skills self-efficacy (Q6, Q8, \& Q9), and technological self-efficacy (Qs 10-12). Survey questions were developed from Schwarzer and Jerusalem's (1995) General Self-Efficacy Scale; Brinkerhoff's (2006) Computer Self-Efficacy Scale; Sam, Othman, \& Nordin's (2005) Computer SelfEfficacy Scale; and Wang, Ertmer, \& Newby's (2004) scale for technology integration.

Interview questions were designed to generate responses from students that would provide insight into how they interpret their experiences in the virtual learning environment, their thoughts and feelings throughout the VR activity, and how they use the VR technology to construct knowledge in order to answer the questions in the assignment.

The following interview questions (IQs) were developed to generate participants' reflections on their experiences using VR:

- IQ1 How would you describe your past experiences with virtual reality technology?

- IQ2 Please describe your most recent experience using virtual reality. What was it like? How did you feel throughout the process? What thoughts went through your mind?

- IQ3 How do you solve problems that come up when you're in VR? Please describe your process of problem solving and how you feel throughout that process.

- IQ4 How do you manipulate and analyze objects in VR? What is that experience like?

- IQ5 What is it like to complete a task in VR? For instance, how do you know when you have found the right area of the model to analyze? How do you know you're right?

Following the interviews, participants reviewed video screen captures of their VR sessions for approximately 15 minutes. They were prompted to reflect on what was happening in the video recording with the following Review Session Prompts (RSPs):

- RSP1: Please tell me what's going through your mind at this point. What are you feeling/thinking?

- RSP2: What did you do just do there? What was your thinking behind that? How did you know how to do that?

- RSP3: What is happening there? Was that expected? What were you thinking or feeling at the time?

\section{VR Activity Design}

The activity that participants carried out during the study was designed in consultation with the instructor of each course, so that the activity would fit seamlessly into the existing curriculum. The purpose was to design an activity that would support teaching and be integrated into the course content and learning objectives in order to reduce the perceived novelty of the VR technology, and instead emphasize the particular pedagogical content being taught. Close collaboration with the Anthropology class instructor resulted in an assignment that was more fully integrated into the course content, was a more appropriate length, and took into consideration the documented characteristics of VR that have been shown to support spatial analysis tasks. The assignment asked students to answer a set of questions (17 in the case of Biochemistry and three in the case of Anthropology) related to that week's course content that required them to analyze 3D models (complex protein structures in the case of Biochemistry, and hominid skulls in the case of the Anthropology) using the VR workstation in order to produce the correct answer.

\section{Recruitment and Data Collection}

After obtaining IRB approval, investigators worked with instructors of two undergraduate courses - Structural Biology (CHEM 4923) and General Anthropology (ANTH 1113) - to arrange for a recruitment session, which took place in the classroom and detailed the history of virtual reality and its applications to education. Students were provided with a recruitment notice and informed consent form; and, subsequently, 34 undergraduates (6 from CHEM 4923 and 28 from ANTH 1113) were recruited. Participants were incentivized to participate through course extra credit and receipt of a $\$ 15$ gift card to the campus computer store upon completion. The assignment took on average 00:26:08 for CHEM 4923 students to complete, and 00:13:17 for ANTH 1113 students to complete. 
Participants were asked to visit the publicly accessible virtual reality workstations at the library to familiarize themselves through an orientation session, in advance of the research study activity. Following a week-long orientation period in which students could drop in and practice using the VR workstations (assisted by student staff at the makerspaces in which the VR workstations are housed), students were contacted via email to arrange for another visit to the VR workstations to participate in the research activity and data collection. After signing informed consent forms, participants filled out basic demographic information and a 12 question pre-test survey that measured self-efficacy (see Table 1 below). Then, students worked with customized VR workstations to answer a set of questions related to the course curriculum (developed in conjunction with the respective instructors). Following the VR-supported activity, students were given a post-activity survey, which asked the same questions measuring self-efficacy, in order to measure any changes to their self-reported scores.

\section{FINDINGS}

Several demographic data points were tracked during the pre-survey portion of the study. The average age of the participants was 19.47 years and there was an approximately equal mix of male and female participants. Participants reported that they had previously engaged with virtual reality, on average, on 1.71 occasions, with a single participant reporting as many as six virtual reality experiences and 10 participants reporting no prior VR experience.

\section{Changes in Self-Efficacy}

Paired, two-sample t-tests (two-tailed) were run in order to see if the mean change in students' scores of self-efficacy were statistically significant. The null hypothesis was that the mean change in self-efficacy for each scale was zero. We found no significant impact (no change in mean scores) on any of the scales for the CHEM 4923 students (see Table 1, below). For some questions (Q's 1, 2, \& 3), post-test scores remained unchanged across participants from this class.

\begin{tabular}{|c|c|c|c|c|c|c|c|}
\hline \multirow{2}{*}{$\begin{array}{l}\text { Survey Questions } \\
(N=6)\end{array}$} & \multicolumn{2}{|c|}{ Pre-test } & \multicolumn{2}{|c|}{ Post-test } & \multirow{2}{*}{$\begin{array}{l}\text { Mean } \\
\text { Change }\end{array}$} & \multicolumn{2}{|c|}{ Paired, 2 sample, t-test } \\
\hline & Mean & $\sigma^{2}$ & Mean & $\sigma^{2}$ & & $\begin{array}{l}\text { t stat (2-tailed, t- } \\
\text { critical }=2.23)\end{array}$ & $\mathbf{P}$ \\
\hline $\begin{array}{l}\text { Q1. I am confident that I could deal efficiently with un- } \\
\text { expected events. }\end{array}$ & 3.83 & 0.17 & 3.83 & 0.17 & 0 & 0 & 1 \\
\hline $\begin{array}{l}\text { Q2. When I am confronted with a problem, I can usu- } \\
\text { ally find several solutions. }\end{array}$ & 4.17 & 0.57 & 4.17 & 0.57 & 0 & 0 & 1 \\
\hline $\begin{array}{l}\text { Q3. I feel that I can handle any minor assignments } \\
\text { that my professors might give to me. }\end{array}$ & 4.67 & 0.27 & 4.67 & 0.67 & 0 & 0 & 1 \\
\hline $\begin{array}{l}\text { Q4. I consider my myself to be very competent in the } \\
\text { skills and knowledge required of my major. }\end{array}$ & 4.00 & 0.40 & 3.83 & 0.57 & -0.17 & 0.42 & 0.69 \\
\hline $\begin{array}{l}\text { Q5. When my professor assigns a major project (final } \\
\text { paper, presentation, etc.), I feel confident that I can } \\
\text { complete the assignment successfully. }\end{array}$ & 4.33 & 0.67 & 4.50 & 0.30 & 0.17 & -0.42 & 0.69 \\
\hline $\begin{array}{l}\text { Q6. I feel confident identifying important features and } \\
\text { characteristics of structures in class activities. }\end{array}$ & 3.50 & 0.70 & 3.33 & 0.67 & -0.17 & 0.35 & 0.73 \\
\hline $\begin{array}{l}\text { Q7. I feel confident finding important features on the } \\
\text { model. }\end{array}$ & 3.50 & 0.70 & 3.67 & 2.27 & 0.17 & -0.24 & 0.82 \\
\hline $\begin{array}{l}\text { Q8. I feel confident comparing and contrasting the } \\
\text { shapes of different parts of the model. }\end{array}$ & 3.83 & 0.97 & 4.00 & 1.20 & 0.17 & -0.28 & 0.79 \\
\hline $\begin{array}{l}\text { Q9. I feel confident judging the relative size of the vari- } \\
\text { ous parts of models. }\end{array}$ & 3.00 & 1.20 & 3.17 & 2.17 & 0.17 & -0.22 & 0.83 \\
\hline Q10. I feel confident that I can use VR technology. & 3.83 & 2.17 & 3.50 & 1.90 & -0.33 & 0.40 & 0.69 \\
\hline $\begin{array}{l}\text { Q11. I feel confident that I can use VR to complete } \\
\text { class assignments without assistance. }\end{array}$ & 3.00 & 0.80 & 3.50 & 1.90 & 0.50 & -0.75 & 0.47 \\
\hline $\begin{array}{l}\text { Q12. I find working with VR very frustrating (reverse } \\
\text { coded). }\end{array}$ & 2.17 & 0.57 & 2.33 & 2.27 & 0.17 & -0.24 & 2.23 \\
\hline
\end{tabular}

Table 1. Survey Questions with Descriptive Statistics for Pre-/post-test \& t-tests (CHEM 4923 Students) 
In the case of the ANTH 1113 students, significant positive changes to mean scores on task-specific (Q8\&Q9) and VR-specific (Q10, Q11\&Q12) scales were found (see Table 2 below). For Q8, "I feel confident comparing and contrasting the shapes of different parts of the model," we found that the ANTH 1113 students' mean scores increased from 3.86 to 4.29 ( $\mathrm{P}=0.050$ ). For Q9, "I feel confident judging the relative size of the various parts of the models," we found that the students' mean scores increased from 3.64 to 4.21 ( $\mathrm{P}=0.001)$. These scores draw on skills related to judging the shape and size of models. For Q10, "I feel confident that I can use VR technology," we found that the students' mean scores increased from 3.89 to 4.33 (P=0.037). For Q11, "I feel confident that I can use VR to complete class assignments without assistance," we found that the students' mean scores increased from 3.61 to 4.21 ( $\mathrm{P}=0.007)$. Finally, for $\mathrm{Q} 12$ (which was the one scale that was reverse coded), "I find working with VR very frustrating," we found that the students' mean scores decreased from 2.11 to 1.71 ( $\mathrm{P}=0.046)$. It is worth noting that the CHEM 4923 students started at a similar "frustration score" of 2.17, but showed no significant change in this score. These three questions (Q10-Q12) were designed to measure participants' technological self-efficacy in regards to the VR technology.

\begin{tabular}{|c|c|c|c|c|c|c|c|}
\hline \multirow{2}{*}{$\begin{array}{c}\text { Survey Questions } \\
(\mathrm{N}=\mathbf{2 8})\end{array}$} & \multicolumn{2}{|c|}{ Pre-test } & \multicolumn{2}{|c|}{ Post-test } & \multirow{2}{*}{$\begin{array}{l}\text { Mean } \\
\text { Change }\end{array}$} & \multicolumn{2}{|c|}{ Paired, 2 sample, t-test } \\
\hline & Mean & $\sigma^{2}$ & Mean & $\sigma^{2}$ & & $\begin{array}{l}\text { t stat (2-tailed, t- } \\
\text { critical }=2.05)\end{array}$ & $\mathbf{P}$ \\
\hline $\begin{array}{l}\text { Q1. I am confident that I could deal efficiently with } \\
\text { unexpected events. }\end{array}$ & 4.11 & 0.32 & 4.29 & 0.29 & 0.18 & -1.97 & 0.057 \\
\hline $\begin{array}{l}\text { Q2. When I am confronted with a problem, I can } \\
\text { usually find several solutions. }\end{array}$ & 4.18 & 0.37 & 4.32 & 0.37 & 0.14 & -1.689 & 0.103 \\
\hline $\begin{array}{l}\text { Q3. I feel that I can handle any minor assignments } \\
\text { that my professors might give to me. }\end{array}$ & 4.36 & 0.31 & 4.43 & 0.33 & 0.07 & -0.70 & 0.490 \\
\hline $\begin{array}{l}\text { Q4. I consider my myself to be very competent in } \\
\text { the skills and knowledge required of my major. }\end{array}$ & 4.07 & 0.37 & 4.07 & 0.22 & 0 & 0.00 & 1.000 \\
\hline $\begin{array}{l}\text { Q5. When my professor assigns a major project (fi- } \\
\text { nal paper, presentation, etc.), I feel confident that I } \\
\text { can complete the assignment successfully. }\end{array}$ & 4.39 & 0.47 & 4.39 & 0.46 & -0.03 & 1.00 & 1.000 \\
\hline $\begin{array}{l}\text { Q6. I feel confident identifying important features } \\
\text { and characteristics of structures in class activities. }\end{array}$ & 3.93 & 0.59 & 4.18 & 0.37 & 0.25 & -1.43 & 0.165 \\
\hline $\begin{array}{l}\text { Q7. I feel confident finding important features on the } \\
\text { model. }\end{array}$ & 4.18 & 0.37 & 4.18 & 0.37 & 0.14 & -1.69 & 0.103 \\
\hline $\begin{array}{l}\text { Q8. I feel confident comparing and contrasting the } \\
\text { shapes of different parts of the model. }\end{array}$ & 3.86 & 0.72 & 4.29 & 0.72 & $0.42^{*}$ & -2.06 & 0.050 \\
\hline $\begin{array}{l}\text { Q9. I feel confident judging the relative size of the } \\
\text { various parts of models. }\end{array}$ & 3.64 & 0.83 & 4.21 & 0.54 & $0.57^{\star *}$ & -3.62 & 0.001 \\
\hline Q10. I feel confident that I can use VR technology. & 3.89 & 0.87 & 4.33 & 0.69 & $0.44^{*}$ & -2.20 & 0.037 \\
\hline $\begin{array}{l}\text { Q11. I feel confident that I can use VR to complete } \\
\text { class assignments without assistance. }\end{array}$ & 3.61 & 0.99 & 4.21 & 0.69 & $0.61^{*}$ & -2.92 & 0.007 \\
\hline $\begin{array}{l}\text { Q12. I find working with VR very frustrating (reverse } \\
\text { coded). }\end{array}$ & 2.11 & 0.84 & 1.71 & 1.02 & $-0.39^{*}$ & 2.09 & 0.046 \\
\hline
\end{tabular}

Table 2. Survey Questions with Descriptive Statistics for Pre-/post-test \& t-tests (ANTH 1113 Students)

\section{DISCUSSION}

While data gathering was conducted without the control conditions present in the laboratory, the effectiveness of the VR workstations and the methods of evaluating them show promise. For the ANTH 1113 students, the significant positive impact on self-efficacy along dimensions related to completion of spatial tasks suggests that the positive attributes of VR technologies identified in lab-based research studies may have a benefit when applied in real-world, course-based activities. The improvement in students' self-efficacy related to successfully executing discipline-specific assignments using virtual reality, especially where those tasks relate to size judgements and other spatial thinking tasks, is also a promising outcome.

\section{Implications for Designing Course Activities}

The results of the study have some important implications for designing VR activities to support discipline-specific learning outcomes. We suspect that the lack of any significant change we observed in CHEM 4923 students' self-efficacy scores and 
the significant positive change in the ANTH 1113 students' self-efficacy scores can be attributed in part to different levels of guidance provided by the project team in helping the faculty member in each class design the activity. In the CHEM 4923 case, the faculty member designed the activity first, and then the project team made some suggestions for improvement. In the case of ANTH 1113, the project team worked with the faculty member from the start of the process of assignment design, ensuring that the activity was designed to specifically draw on the particular analytic affordances of VR. An initial analysis of the qualitative data collected in this study (to be discussed in greater detail in a future paper) also revealed that for the CHEM 4923 students some aspects of the VR environment that were designed to produce realistic objects, such as shadows, interfered with their visual analysis. These findings suggest that, in order to have a positive impact on students' self-efficacy, librarians and technologists should work closely with course instructors to ensure that VR activities are designed in consideration of both the types of spatial skills that VR is particularly apt at supporting and the particular analytic needs of students working in specific disciplines.

\section{Methodological Considerations}

While the results of this study suggest that VR can have a positive impact on student self-efficacy, our instruments need further development to ensure their validity. We need to further validate the survey instrument by analyzing correlations between scales to identify those that might be measuring the same underlying construct, look at the internal consistency of scores over multiple iterations of the study to assess the reliability of the survey, and most importantly, collect data about student learning outcomes (exam scores, final course grade, or other measures) and correlate with self-efficacy scores. It is hoped that these initial findings and methodological implications drawn from the quantitative data will serve as a guide for other librarians and researchers who are beginning to study and adopt these emergent and rapidly changing technologies in their institutions.

\section{Limitations and Future Directions}

These results are contingent on both the systems employed (e.g. the hardware/software idiosyncrasies of the specific virtual reality workstation implementation) and the instructional design of the associated activity. Lighting, and the ability (or inability) to quickly adjust ambient lighting conditions to reveal surface and geometric details of 3D content, were repeatedly mentioned as a feature that should be improved. Further, the current technological immaturity of virtual reality as a tool for scholarship means that issues related to "simulator sickness" (nausea due to the simulated motion of VR spaces) for example, must be taken into account when determining the appropriate duration of a virtual reality-based course assignment (Lin, et al., 2002). Sample size was an issue in this study as well, especially with regards to the CHEM 4923 class, which had only seven students enrolled, making it difficult to compare outcomes to the larger Anthropology class. Further studies will attempt to address this by selecting classes with comparable class sizes from which to recruit research participants.

Student learning outcomes were not a focus of this study, so participants' assignments were not graded. Therefore, data on selfefficacy cannot be correlated with learning outcomes. In addition, the site of data collection was not a controlled environment. Student participants were free to seek verbal guidance from investigators during the course of their VR activity. Future research will control for these variables in order to study the impact of VR on learning outcomes and performance dimensions of task completion (e.g., speed and accuracy). Another limitation of the study design is that it does not enable comparison of the benefits of VR to flat-screen based visualizations. In further refining the research design, a flat-screen 3D visualization could be used with a control group to further pinpoint the impact of VR on self-efficacy.

Finally, the qualitative data gathered during the post-activity interview phase of this study is rich, and provides many ways forward both for informing VR system design and formulation of future studies. Once fully analyzed, the qualitative data will provide rich description to students' experiences of VR and help to better understand how the technological affordances of VR shape students' self-efficacy.

\section{CONCLUSION}

Students' use of VR does not happen in a vacuum; their experiences of any technology or learning environment are embedded in their everyday lives as undergraduate students and the institutional contexts of the classroom and the academic library. Assessing the impact of VR use on students' self-efficacy in the context of a real-world, class-based activity offers a holistic approach to evaluating the impact of VR in an academic library context. Completing our analysis of the qualitative data generated through this study will further develop a rich picture of students' embodied experiences, with findings that will help guide other library professionals in developing VR platforms and the tools with which to effectively evaluate them.

\section{REFERENCES}

Abbitt, J.T. (2011). An investigation of the relationship between self-efficacy beliefs about technology integration and technological pedagogical content knowledge (TPACK) among preservice teachers. Journal of Digital Learning in Teacher Education, 27(4), $134-143$.

Angulo, A. (2013). On the design of architectural spatial experiences using immersive simulation. In Proceedings of EAE 11: Envisioning 
Architecture: Design, Evaluation, Communication (pp. 151-158). Italy: Milan.

Bandura, A. (1977). Self-efficacy: Toward a unifying theory of behavioral change. Psychological Review, 84(2), $191-215$.

Bowman, D. A., \& McMahan, R. P. (2007). Virtual reality: How much immersion is enough? Computer, 40(7), $36-43$.

Brinkerhoff, J. (2006). Effects of a long-duration, professional development academy on technology skills, computer self-efficacy, and technology integration beliefs and practices. Journal of Research on Technology in Education, 39(1), 22-43.

Bronack, S., Cheney, A., Reidl, R., \& Tashner, J. (2008). Designing virtual worlds to facilitate meaningful communication: Issues, considerations, and lessons learned. Technical Communication, 55(3), 261-269.

Brooke, J. (1996). SUS: A quick and dirty usability scale. Usability Evaluation in Industry, 189(194), 4-7.

Budd, J. (2005). Phenomenology and information studies. Journal of Documentation, 61(1), 44-59.

Budd, J., Hill, H., \& Brooke, S. (2010). Inquiring into the real: A realist phenomenological approach. Library Quarterly, 80, $267-84$.

Carr, D., Oliver, M., \& Burn, A. (2010). Learning, teaching and ambiguity in virtual worlds. In A. Peachy, J. Gillen, D. Livingstone, and S. Smith-Robbins (eds.), Researching learning in virtual worlds (pp. 17-31). London: Springer.

Cook, M. (2018). Virtual serendipity: Preserving embodied browsing activity in the 21 st century research library. The Journal of Academic Librarianship, 44(1), 145-149.

Dalbello, M. (2005). A phenomenological study of an emergent National Digital Library, Part I: Theory and methodological framework. Library Quarterly, 75(4), 391-420.

Dalgarno, B., \& Lee, M. (2010). What are the learning affordances of 3-D virtual environments? British Journal of Educational Technology, 4l(1), 10-32. http://dx.doi.org/10.1111/j.1467-8535.2009.01038.x

Deutschmann, M., Panichi, L., \& Molka-Danielsen, J. (2009). Designing oral participation in Second Life: A comparative study of two language proficiency courses. ReCALL, 21(2), 206-226.

Donalek, C., Djorgovski, S. G., Cioc, A., Wang, A., Zhang, J., Lawler, E., ... \& Davidoff, S. (2014, October). Immersive and collaborative data visualization using virtual reality platforms. In Proceedings of IEEE International Conference on Big Data (pp. 609-614). IEEE.

Forsberg, A., Katzourin, M., Wharton, K., \& Slater, M. (2008). A comparative study of desktop, fishtank, and cave systems for the exploration of volume rendered confocal data sets. IEEE Transactions on Visualization and Computer Graphics, 14(3), 551-563.

Haycock, K., \& Kemp, J.W. (2008). Immersive learning environments in parallel universes: Learning through Second Life. School Libraries Worldwide, 14(2) 89-97.

Holmberg, K., \& Huvila, I. (2008). Learning together apart: Distance education in a virtual world. First Monday, 13(10), http://firstmonday.org/htbin/cgiwrap/bin/ojs/index.php/fm/article/view/2178/2033

Jang, S., Vitale, J. M., Jyung, R. W., \& Black, J. B. (2017). Direct manipulation is better than passive viewing for learning anatomy in a three-dimensional virtual reality environment. Computers \& Education, 106, 150-165.

Laha, B., Bowman, D. A., \& Socha, J. J. (2014). Effects of VR system fidelity on analyzing isosurface visualization of volume datasets. IEEE Transactions on Visualization and Computer Graphics, 20(4), 513-522.

Limp, F., Payne, A., Simon, K., Winters, S., \& Cothren, J. (2011). Developing a 3-D digital heritage ecosystem: From object to representation and the role of a virtual museum in the 21st century. Internet Archaeology, 30.

Lin, J. W., Duh, H. B. L., Parker, D. E., Abi-Rached, H., \& Furness, T. A. (2002). Effects of field of view on presence, enjoyment, memory, and simulator sickness in a virtual environment. In Proceedings of IEEE Virtual Reality Conference (pp. 164-171). IEEE.

Praslova-Førland, E., Sourin, A., \& Sourina, O. (2006). Cybercampuses: Design issues and future directions. Visual Computer, 22(12), $1015-1028$.

Ragan, E. D., Kopper, R., Schuchardt, P., \& Bowman, D. A. (2013). Studying the effects of stereo, head tracking, and field of regard on a small-scale spatial judgment task. IEEE Transactions on Visualization and Computer Graphics, 19(5), 886-896.

Sam, H. K., Othman, A. E. A., \& Nordin, Z. S. (2005). Computer self-efficacy, computer anxiety, and attitudes toward the Internet: A study among undergraduates in Unimas. Journal of Educational Technology \& Society, 8(4), 205-219.

Schwarzer, R., \& Jerusalem, M. (1995). Generalized Self-Efficacy scale. In J. Weinman, S. Wright, \& M. Johnston, Measures in health psychology: A user's portfolio. Causal and control beliefs (pp. 35-37). Windsor, UK: NFER-Nelson.

Seth, A., Vance, J. M., \& Oliver, J. H. (2011). Virtual reality for assembly methods prototyping: A review. Virtual Reality, 15(1), 5-20.

Sheehy, K. (2010). Virtual environments: Issues and opportunities for researching inclusive educational practices. In A. Peachey, J. Gillen, D. Livingstone, and S. Smith-Robbins (eds.), Researching learning in virtual worlds (pp. 1-15). London: Springer.

Smith, J. A., Flowers, P., \& Larkin, M. (2009). Interpretive phenomenological analysis: Theory, method and research. Los Angeles: Sage.

Suorsa, A., \& Huotari, M. L. (2014). Knowledge creation and the concept of a human being: A phenomenological approach. Journal of the Association for Information Science and Technology, 65(5), 1042-1057. 
Suorsa, A.R. (2017). Knowledge creation and play: A phenomenological study within a multi-professional and multi-organizational community. Journal of Documentation, 73(6) 1167-1191.

Tan, W.-K., Tan, C.-H., \& Teo, H.-H. (2012). Conveying information effectively in a virtual world: Insights from synthesized task closure and media richness. Journal of the American Society for Information Science and Technology, 63(6), 1198-1212.

Van Dam, A., Laidlaw, D. H., \& Simpson, R. M. (2002). Experiments in immersive virtual reality for scientific visualization. Computers \& Graphics, 26(4), 535-555.

Van Scoy, A., \& Evenstad, S.B. (2015). Interpretative phenomenological analysis for LIS research. Journal of Documentation, 71(2), 338357. https://doi.org/10.1108/JD-09-2013-0118

Wang, L., Ertmer, P. A., \& Newby, T. J. (2004). Increasing preservice teachers' self-efficacy beliefs for technology integration. Journal of Research on Technology in Education, 36(3) 231-250.

Warburton, S. (2009). Second Life in higher education: Assessing the potential for and the barriers to deploying virtual worlds in learning and teaching. British Journal of Educational Technology, 40(3), 414-426.

$81^{\text {st }}$ Annual Meeting of the Association for Information Science \& Technology | Vancouver, Canada $\mid 10-14$ November 2018 Author(s) Retain Copyright 